\title{
Selecting subjects for participation in clinical research: one sphere of justice
}

\author{
Charles Weijer Dalhousie University, Halifax, Nova Scotia, Canada
}

\begin{abstract}
Recent guidelines from the US National Institutes of Health (NIH) mandate the inclusion of adequate numbers of women in clinical trials. Ought such standards to apply internationally? Walzer's theory of justice is brought to bear on the problem, the first use of the theory in research ethics, and it argues for broad application of the principle of adequate representation. A number of practical conclusions for research ethics committees (RECs) are outlined. Eligibility criteria in clinical trials ought to be justified by trial designers. Research ethics committees ought to question criteria that seem to exclude unnecessarily women from research participation. The issue of adequate representation should be construed broadly, so as to include consideration of the representation of the elderly, persons with HIV, mental illness and substance abuse disorders in clinical research.
\end{abstract}

(Fournal of Medical Ethics 1999;25:31-36)

Keywords: Cinical trials; eligibility determination; patient participation; medical ethics; justice; women; US National Institutes of Health

Research ethics committees have long been concerned with ethical issues arising from the selection of subjects for research participation. Research ethics committees scrutinise study eligibility criteria to ensure that research neither preys upon the vulnerable nor excludes without good reason subjects who may benefit from study participation. In 1992, Dresser drew attention to a new ethical problem: the systematic exclusion of women from clinical research. ${ }^{1}$ Women have been excluded from certain types of clinical research for years, she claimed, and as a result there is a relative lack of knowledge regarding optimal treatment for some medical conditions affecting women. In response, the United States National Institutes of Health now require the proportionate representation of women in NIH-funded clinical trials and give institutional review boards (the REC equivalent in the US) part of the responsibility to enforce this requirement. ${ }^{2}$
The enforcement of the NIH guidelines as such is limited by the jurisdiction of the National Institutes of Health to NIH-funded clinical trials. The applicability of the principles articulated in the NIH guidelines depends on moral justifications offered in their support. Thus, in order to draw lessons from the NIH guidelines for RECs internationally, we must examine the ethical underpinnings of the impetus to include women in representative numbers in clinical trials.

While ethical issues related to subject selection for study participation are typically framed in terms of distributive justice, ie, the equitable allocation of goods to individuals, alternative approaches to justice may provide a richer moral account. One alternative approach is taken by feminist theorists who understand justice as the elimination of oppression. ${ }^{3}$ Thus, the inclusion or exclusion of individuals from research participation is just insofar as it eliminates oppression.

The argument to include adequate numbers of women in clinical trials may be strengthened if yet another approach to justice can be marshalled in favour of the cause. First, a moral conclusion may be viewed as more robust if different ethical theories argue for it. Second, a non-feminist approach may be more convincing to those ill-disposed to feminist theory. Walzer presents an appealing and novel approach to justice in Spheres of fustice. $^{4}$ Walzer's view of justice as the elimination of domination is influential in political philosophy. According to the results of a Bioethicsline search (1973 to 1997), however, his theory has yet to be applied in research ethics. Does Walzer's view of justice support the representative inclusion of women in clinical trials? And if so what implications follow for RECs?

\section{Spheres of justice}

For Walzer, justice is not about ensuring that everyone has an equal number of things (ie, simple equality), rather its aim is to free society from domination. Domination manifests itself in different ways in various societies, but it is always mediated by some social good whether money, or birth and blood. Accordingly, he sets himself the task of 
describing a society that has been freed of domination, a complex egalitarian society. Setting himself apart from other justice theorists, Walzer approaches the question through a careful examination of history and culture. Goods are distributed in accord with their meaning for members of a particular society. For example, a bit of food may represent sustenance or a religious offering; and what is to be done with it depends on which of these meanings it is given. ${ }^{5}$

It follows that the just distribution of social goods cannot be understood by a rule universal in application. Rather each set of goods (community membership, security and welfare, money and commodities, office, hard work, free time, education, kinship and love, divine grace, recognition, and political power) operates within a sphere governed by its own rules of distribution. Thus, one type of injustice is a failure to distribute a particular good in accord with the norms of its particular sphere.

A second type of injustice is domination, that is, a transgression of the boundaries between spheres. Domination exists when one good is converted into another when there exists no intrinsic connection between the two, for example, buying votes with money. In other words, domination exists when one good commands control of a wide range of goods. The elimination of domination renders such transactions impermissible, but does not prevent unequal distributions of individual goods. In the complex egalitarian society "no citizen's standing in one sphere or with regard to one social good can be undercut by his standing in some other sphere, with regard to some other social good". 6

Conventional approaches to distributive justice have not focused on the elimination of domination, rather they have targeted monopoly, the control of a dominant good by a small group of people. They ask: how can money be distributed more fairly or more equally? Merely redistributing wealth, however, is a false or, at best a temporary, solution. Some people will save their money, others will spend it, still others will, through their own entrepreneurship, accumulate wealth; and so, the distribution would soon be unequal again. If government intervened repeatedly to ensure an equal distribution, money would no longer be the dominant good, political power would be. Walzer's solution is to address domination directly.

\section{Medical care and research}

Medical care is classified in the sphere of security and welfare, a sphere containing goods which the community must provide for its members. But for which needs must the community provide? Sepa- rate communities at different times have answered. this question in disparate ways: for some, commote defence is a priority and caring for the poor an the sick is not. Priorities can change over time as well.

In contemporary Canada, the United State $\odot$ and the United Kingdom, medical care is an important social good. But providing medical carb and conducting medical research is expensive and, thus, communal effort is required. The coms munity has stepped in to pay for basic medici care. Once communal provision of a good occurs the good must be distributed in accord with need and in recognition of the underlying equality of communal membership. ${ }^{7}$ Thus, the good of health care must be distributed in accord with need, that is, proportionate to illness.

\section{Other benefits}

Of course the provision of medical care not only aids the sick, it generates other benefits. Healtkg care workers derive incomes from their work; skil $-\overline{-}$ ful practitioners derive prestige and respect; and in turn, this may translate into other goods such as political office. Viewed this way, a number of spheres of justice seem to vie for control of th $\bar{\emptyset}$ distribution of health care. This conundrum requires scrutiny of the meaning of that good fo? this community to determine its primary meaning and thus its primary distributive rules. Within out society, health care is provided by the communit because health and longevity - not the income prestige, or career advancement of, for example physicians - is a communal priority. One can imagine communities in which these other good? might be key, but it seems unlikely that health carê would be provided communally.

Walzer places medical research in the sphere of security and welfare because it is part of the com mon effort required to provide medical care Without research we could not be sure that treats ments in use actually work nor could we developu effective treatments for currently untreatable dis 0 ease. Thus, research is a necessary means to the provision of medical care, rather than a good if itself.

Indeed, the intimate association between medi=0 cal research and medical practice is perhaps $\vec{\Phi}$ relatively recent development. ${ }^{8}$ At the turn of the century, a number of medical advances, including Erhlich's discovery of Salvarsan, the first effective treatment for syphilis, began to change the public's perception of medical treatment. Diseased like cancer became "medicalised" and people came to invest in science their hopes for progress in the fight against disease. 
Thus the connection between improvements in medical treatment and medical science were solidified: cancer was seen as "both a looming threat to civilization and a disease that brilliant scientists were beginning to conquer". ${ }^{10}$ But if it was to be conquered, concerted government action was required. ${ }^{11}$ Cancer research was publicly supported to the end of improving treatment for the disease and subsequent funding measures, including the declaration of a "war against cancer," have been justified and accepted on this basis. ${ }^{12}$

\section{The distributive logic of medical research}

If the distribution of knowledge generated from medical research is to "recognize and uphold the underlying equality of membership," 13 the results of medical research must be applicable to the breadth of community members afflicted with a particular illness. Clinical trials have a variety of purposes. Phase I trials examine toxicity and other pharmacological properties of new drugs. Phase II trials seek to establish whether a new drug has an effect in a particular disease. In many cases, though perhaps not all, phase III clinical trials aim to change medical practice, for example by comparing a new treatment with the best standard treatment. Just eligibility criteria will further the end of the trial and thus, eligibility criteria must select subjects solely in accord with the exigencies of medical care and science. If an eligibility criterion selects (or excludes) subjects because of their standing in another sphere, without reference to the requirements of medical care or science, the criterion involves boundary crossing and is unjust.

Eligibility criteria are justified by appeal to the purpose of the clinical trial. Phase I and phase II clinical trials, by and large, aim to answer narrow biological questions: how is this drug broken down in the body, does it have any effect on this particular disease? A more restrictive approach to criteria for trial eligibility is justified in such trials. If, however, phase III clinical trials aiming to change clinical practice are to be applicable to the community at large (generalisable), then the study population must be representative of patients in clinical practice.

A natural tension exists between phase III trials that are scientifically fastidious and those that are widely generalisable. (Indeed, North American trialists tend towards fastidious studies with restrictive eligibility criteria, and trialists on the other side of the Atlantic often prefer broadly inclusive designs.) A fastidious approach is likely to appeal to clinician-scientists who embrace the ethos (and the aesthetic) of the controlled laboratory experiment. ${ }^{14}$ But such narrowly focused studies produce results that are only applicable to a narrow segment of the patient population. A variety of other goods may be served by fastidious trials: investigator prestige and recognition, academic advancement, and even "purer" (though less clinically relevant) knowledge. But each of these considerations originates from spheres separate from that of security and welfare. In phase III trials, eligibility criteria that heed the distributive rules of the sphere of security and welfare will minimise restrictions to the study populations and will justify necessary restrictions carefully and in a manner open to scrutiny by research ethics committees.

\section{Unjust inclusion and exclusion as domination}

The discussion thus far has focused on the just distribution of medical knowledge according to the norms of the sphere of welfare and security. There is another relevant category of justice: justice as the absence of boundary-crossing between spheres (domination). Domination occurs when an eligibility criterion selects or excludes subjects because of their standing in another sphere, without reference to the requirements of medical care or science. Medical research is unjust if it selects subjects solely on the basis of wealth, education, political empowerment, gender, citizenship, employment or religious belief.

Well-known examples of unethical research have included subjects in research on the basis of their standing in other spheres, and without reference to the exigencies of medical care and science. Notorious experiments conducted by Nazi physicians in the second world war preyed on the politically disempowered, including political prisoners, Jews, Gypsies and homosexuals. The Tuskegee syphilis study observed the effects of untreated syphilis for decades after penicillin became available. ${ }^{15}$ The study was unjust in part because it exclusively enrolled subjects who were poor, uneducated and Afro-American.

But domination can cut both ways: subjects can be unjustly included in research, or they can be unjustly excluded. When domination takes the form of unjust inclusion, subjects are exposed to the risks associated with the research; when domination takes the form of unjust exclusion, other harms may be incurred. Members of excluded groups may be exposed to ineffective treatments, unexpected side effects may occur, or a lack of information may lead to delays in the diagnosis and treatment of disease. ${ }^{16}$ 


\section{Exclusion of women as domination}

Until recently, women were excluded from earlystage studies of new drugs. ${ }^{17}$ The evidence for exclusion of women from late-stage studies is strongest in cardiology trials. ${ }^{18}$ (There is, however, evidence that women have not been excluded from cancer trials. ${ }^{19}$ ) The exclusion of women from trials of cardiovascular disease may have a negative impact on the health care that women with heart disease receive. Despite the fact that gender is not a factor predictive of heart disease, women undergo fewer major diagnostic and therapeutic procedures than men. ${ }^{20}$ By the time women actually receive heart surgery, their disease is more advanced and they have a higher operative mortality rate. ${ }^{21}$ Two reasons have been given for the exclusion of women from phase III trials: female reproductive physiology is a "complicating factor" in scientific studies, and concern for toxicity of experimental treatments to fetuses. ${ }^{22}$

Walzer recognises that the family is an important unit within contemporary society. Particular rules of distributive justice apply in what Walzer interchangeably calls the sphere of "kinship and love" and that of "personal relations, domestic life, reproduction and child rearing". Women have an important role to play within the family, one that involves carrying a child to term, giving birth to it, and caring for it after birth. While this reproductive role has a central place in the family, women have been wrongly excluded from other social roles on the basis of this familial role, on the basis of their standing within the sphere of kinship and love. ${ }^{23}$

The exclusion of women of reproductive age and women in general from medical research is based on the reproductive role that women fulfil within the family. Studies have excluded women because of the fact that the reproductive physiology of women is viewed as a "complicating factor". Although men and women share many more physiological similarities than differences, differences none the less exist. But the reproductive physiology of women is a complication only if male physiology is taken to be the norm. ${ }^{24}$ This characterisation of women - and, importantly, not men - in terms of their reproductive role and their exclusion on this basis from scientific studies is domination.

Women of reproductive age have been excluded from research on the grounds that experimental drugs may be harmful to fetuses. When a given drug is known to be teratogenic, excluding pregnant women from participation in the study is a necessary precaution. But, even in such cases of clear risk to the fetus, the exclusion of all women of reproductive age from a study seems to characterise women solely on the basis of their reproductive role.

Patterson and Emanuel describe two studie involving drugs with the potential to harm the developing fetus: 13-cis retinoic acid for the prevention of secondary lung cancer in one trials and finasteride for prostate cancer in the other. ${ }^{25}$ In the 13-cis retinoic acid study, all women of reproductive age were excluded; in the finasteridg study, men were merely required to use at effective contraceptive method. If men are truste to use effective contraception when there is risk to the fetus, then why are women not similarly trusted ${ }^{26}$ In both trials it was reasonable to take steps to protect fetuses from harm. The exclusiog of all women of reproductive age in the one triat however, clearly characterises and excludeg women on the basis of their reproductive role and is therefore an instance of domination. If the exclusion of all women of reproductive potential is unjust in the case of a clearly teratogenic druछ then, a fortiori, it is unjust when evidence for teratogenicity is less clear or lacking.

If women are to receive an allocation of medica care which upholds "the underlying equality $\overline{\text { fif }}$ membership" in the community, ${ }^{27}$ they must bo included in adequate numbers in medical re search. Clinical trialists must provide clear justifg cations for any exclusion and evidence to support such exclusions ought to be carefully examine Even in the exceptional case when strong evidence. exists that women may respond differently thas men to a particular treatment, the equality provis sion does not seem to allow them to be excludee. Rather, a larger study ought to be mounted tô address any gender differences that may b를 present.

\section{New areas for ethical attention}

Insofar as the unjust inclusion of groups io research is driven by widely held beliefs about the worth of members of such groups, the unjust exclusion of other groups is driven by sociall\% constructed notions of deviation from the norm of vulnerability. It may be that groups other that women have been wrongly excluded from clinicas trials. The elderly have long been excluded fromo cancer clinical trials despite the fact that the carry the heaviest burden of the disease. ${ }^{28}$ Oldees patients have been excluded from trials on the presumption that they are more susceptible to the toxic effects of cancer therapy, yet the assumpo tions upon which those policies were based have not been substantiated by empirical scrutiny. ${ }^{29}$

Persons with a history of drug or alcohol abuse are often excluded from clinical trials. Such 
persons are barred from participation because they are thought to be unreliable: they are unlikely to comply with treatments and required follow-up visits. There is, however, no empirical basis for this claim. ${ }^{30}$ Indeed, in the context of some clinical trials compliance may be adequate even in persons with active drug abuse (let alone in those with a mere history of abuse). ${ }^{31}$

Other groups are also often excluded without a clearly compelling justification. Otherwise healthy persons who carry the Human Immunodeficiency Virus (HIV) are often regarded as ineligible for study participation. But are they really more likely to suffer adverse events? Persons with a history of mental illness are also sometimes excluded. But are they more likely to be incapable of giving informed consent? These questions deserve empirical attention.

\section{Implications for research ethics committees}

The NIH guidelines set an important precedent in the regulation of clinical research. They identify the systematic exclusion of women from research as an important ethical issue and give ethics committees the authority to challenge eligibility criteria that restrict the generalisability of study findings. But the jurisdiction of these requirements is limited to studies funded by the NIH. By examining the moral basis of clinical research through Walzer's theory of justice, I have established principles applicable to communities in which medical care and research is a community priority and is, therefore, provided for communally.

A number of implications follow for research ethics committee review of phase III clinical trials aiming to change clinical practice.

1. Eligibility criteria must select subjects solely in accord with the exigencies of medical care and science. If research ethics committees are to scrutinise criteria, trial designers must provide an explicit justification for each eligibility criterion within the clinical trial protocol.

2. Research ethics committees must question eligibility criteria that seem to select potential research subjects solely on the basis of wealth, education, political empowerment, gender, citizenship, employment or religious belief.

3. Women must be included in adequate numbers in phase III studies. Research ethics committees must question criteria that exclude, without compelling justification, women from research participation. In a study of a teratogenic drug, it is reasonable to exclude pregnant women from participation and to require all participants to use adequate birth control measures. The exclusion of all women of reproductive potential is, however, unjust. Questions of legal liability often loom large in such cases. Clearly potential subjects must be carefully informed of risks and benefits of research participation. Pharmaceutical companies ought to recognise that the potential liability associated with releasing a drug onto the market that is inadequately tested in women likely exceeds the legal risk stemming from including women of reproductive potential in clinical trials. ${ }^{32}$

4. Other groups, perhaps including the elderly, people with a history of alcohol or drug abuse, otherwise health people with HIV, and those with a history of mental illness, have been unjustly excluded from research participation. Research ethics committees ought to ensure that the exclusion of such groups is carefully justified and that these justifications rest on empirically substantiated claims. Efforts to ensure that phase III trials that aim to change clinical practice are broadly inclusive rest on both an ethical and scientific foundation. Large simple trials have been advocated as a way of efficiently and reliably advancing treatment for common diseases, including cancer and heart disease. Pragmatic approaches to trial design recognise both reliability and clinical relevance as desirable: the criteria for a good trial are fairly straightforward: ask an important question and answer it reliably. The importance of the question depends to a large extent on its clinical relevance. It is obvious that the more widely applicable are the results of a clinical trial, the more relevant and valuable are those results. ${ }^{33}$

More recently, the Cochrane Collaboration has sought to enhance the impact of clinical trials on medical practice through the dissemination of systematic reviews of health care research. ${ }^{34}$ The analysis presented in this paper highlights the role the research ethics committee has in promoting clinically relevant trials and, ultimately, the health of the community.

\section{Acknowledgments}

The author's work is supported by an Operating Grant and Scholar Award from the Medical Research Council of Canada. The author is grateful to Professor Karen Lebacqz, the late Professor Benjamin Freedman and Robert Crouch for their helpful comments on earlier drafts of this paper. The author would like to thank the two anonymous reviewers of the 
Fournal of Medical Ethics for their insightful suggestions.

Charles Weijer, MD, PhD, is Assistant Professor of Medicine at Dalhousie University, Halifax, Nova Scotia, Canada.

\section{References}

1 Dresser R. Wanted single, white male for medical research. Hastings Center Report 1992; 22: 24-9.

2 Department of Health and Human Services, National Institutes of Health. NIH guidelines on the inclusion of women and minorities as subjects in clinical research. Federal Register 1994; 59: 14508-13.

3 Sherwin S. Women in clinical studies: a feminist view, and DeBruin DA. Justice and the inclusion of women in clinical studies: a conceptual framework. In: Mastroianni AC, Faden R, Federman D, eds. Women and health research: ethical and legal issues of including women in clinical studies. Volume ii: workshop and commissioned papers. Washington, DC: National Academy Press, 1994: 11-17, 127-50.

4 Walzer M. Spheres of justice: a defence of pluralism and equality. New York: Basic Books, 1983.

5 See reference 4: 7 .

6 See reference $4: 19$.

7 See reference 4: 88

8 Patterson JT. The dread disease: cancer and modern American culture. Cambridge, MA: Harvard University Press, 1987.

9 See reference 8: 47 .

10 See reference 8: 124 .

11 See reference $8: 78$

12 Committee on Labor and Public Welfare, United States Senate. National program for the conquest of cancer: report of the national panel of consultants on the conquest of cancer. Washington, DC: US Government Printing Office, 1971:1

13 See reference $4: 84$

14 Begg CB, Engstrom PF. Eligibility and extrapolation in cancer clinical trials. Fournal of Clinical Oncology 1987; 5: 962-98.

15 Jones JH. Bad blood: the Tuskegee syphilis experiment. New York: Free Press, 1993.

16 Mastroianni AC, Faden R, Federman D, eds. Women and health research: ethical and legal issues of including women in clinical studies. Volume I. Washington, DC: National Academy Press, 1994: 75-83.

17 Food and Drug Administration. General consideration for the clinical evaluation of new drugs. Washington, DC: US Government Printing Office, 1977. Publication no: HEW (FDA) 77-3040.
18 General Accounting Office. Women's health: FDA needs to ensuri. more study of gender differences in prescription drug testing. Wast ington, DC: US Government Printing Office, 1992. Publi cation no: GAO/HRD-93-17. See also reference 3: 151-73.

19 Ungerleider RS, Friedman MA. Sex, trials, and datatape fournal of the National Cancer Institute 1991; 83: 6-7.

20 Ayanian JZ, Epstein AM. Differences in the use of procedur between women and men hospitalized for coronary artery di⿺ ease. New England fournal of Medicine 1991; 325: 221-5; anat Steingart RM, Packer M, Hamm P, Coglianese ME, Gersh B, Geltman EM et al. Sex differences in the management के coronary artery disease. New England foumal of Medicine $199 \mathrm{~L}$ 325:226-30.

21 Council on Ethical and Judicial Affairs, American Medic Association. Gender disparities in clinical decision makin fournal of the American Medical Association 1991; 266: 559-6 ఖ্ণ

22 See reference 16: 108-27, 175-202.

23 See reference $4: 240$.

24 See reference 16:113.

25 Patterson WB, Emanuel EJ. The eligibility of women for clindw cal research trials. Fournal of Clinical Oncology 1995; $13: 293-9$.

26 See reference 25: 297.

27 See reference $4: 84$.

28 Trimble EL, Carter CC, Cain D, Freidlin B, Ungerleider RS Friedman MA. Representation of older patients in canc $\Phi$ treatments trials. Cancer 1994; 74 (suppl): 2208-14

29 Giovanazzi-Bannon S, Rademaker A, Lai G, Benson A E్ Treatment tolerance of elderly cancer patients entered one phase ii clinical trials: an Illinois cancer center study. fournal of Clinical Oncology 1994; 12: 2447-52; and Christman K, Muse HB, Case LD, Stanley V. Chemotherapy of metastatic brea@ cancer in the elderly: the Piedmont oncology association experience. Foumal of the American Medical Association 199 268: $57-62$.

30 Hughes JR. Exclusion of "Noncompliant" individuals from clinical trials. Controlled Clinical Trials 1993; 14: 176-7.

31 Harrison K, Vlahov D, Jones K, Charron K, Clements M Medical eligibility, comprehension of the consent process, an retention of injection drug users recruited for an HIV vaccinc trial. Fournal of Acquired Immune Deficiency Syndromes ar Human Retrovirology 1995; 10: 386-90.

32 See reference 16: 128-74.

33 Yusuf S, Held P, Teo KK. Selection of patients for randomize controlled trials: implications of wide or narrow eligibiliti criteria. Statistics in Medicine 1990; 9: 73-86.

34 Bero L, Rennie D. The Cochrane Collaboration. Preparin maintaining, and disseminating systematic reviews of the effects of health care. Fournal of the American Medic Association 1995; 274: 1935-8.

\section{News and notes}

\section{Ethics of Clinical Research in Developing Countries}

The Nuffield Council on Bioethics is to hold a two-day workshop, February 22-23 1999 on the ethics of clinical research in developing countries. Amongst issues addressed will be: the adequacy of existing guidelines; the ethics of externally funded research in developing countries; the ethical issues highlighted by AIDS vaccine trials; non-therapeutic research and consent, and what happens once research is completed.

The workshop will be funded by the Medical Research Council, the Wellcome Trust and the UK
Government Department for International Development.

For further information please contact: Dr Sandy Thomas, Director, Nuffield Council on Bioethics: 0171 631 0566; Liz Morgan-Lewis/Dawn Duncan, Medical Research Council press office: 0171637 6017/6011; Catherine Nestor/Noorece Ahmed, Wellcome Trust press office: $01716118846 / 8540$; Lisa Louis, Information Officer, The Department for International Development: 01719170680 . 